\title{
Biological Properties of Phospholipase C Purified from a Fleecerot Isolate of Pseudomonas aeruginosa
}

\author{
By J. C. CHIN* AND J. E. WATTS $\uparrow$ \\ Immunology, Central Veterinary Laboratory, Department of Agriculture, New South Wales, \\ Roy Watts Road, Glenfield, NSW 2167, Australia
}

(Received 9 December 1987; revised 11 April 1988)

\begin{abstract}
A role for one of many exocellular enzymes produced by Pseudomonas aeruginosa phospholipase $\mathrm{C}$ (PLC) - as a prime candidate virulence factor in fleecerot dermatitis has been examined. The addition of Tween 80 in tryptose minimal medium effectively perturbed the membrane system of a field isolate of $P$. aeruginosa, resulting in increased production and release of a periplasmic enzyme marker, alkaline phosphatase (AP), and also of PLC. PLC activity levels in the culture supernatant were 10- to 15-fold higher in the presence of Tween than in its absence. Apart from AP, the culture medium contained little or no detectable proteolytic enzyme activity, thereby facilitating the partial purification of a haemolytic form of PLC by anion-exchange chromatography. This enzyme, when injected intradermally into the skin of sheep, elicited histopathological lesions virtually identical to those seen in naturally occurring fleecerot. In addition, serum from each of eight sheep afflicted with fleecerot contained high levels of circulating anti-PLC antibody activity when assayed by ELISA. Since these antibodies did not affect the enzymic function of PLC, it is likely that they do not bind to, or are incapable of conformational modification of, the active site.
\end{abstract}

\section{INTRODUCTION}

Pseudomonas aeruginosa is the predominant bacterium isolated from dermatitic lesions of sheep suffering from fleecerot (Burrell et al., 1982b). During the rainy season, high humidity and wet fleece provide ideal conditions for the proliferation of $P$. aeruginosa at the skin surface. Invariably, such rapid bacterial growth exacerbates the mild dermatitis normally associated with transient wetting (Hollis et al., 1982) and this subsequently develops into a superficial inflammatory condition with seropurulent exudation and production of putrefactive odours attractive to the blowfly, Lucilla cuprina (Meritt \& Watts, 1978). Together the predisposing condition of fleecerot dermatitis and flystrike poses a serious economic problem to wool production.

Although little is known about the role of $P$. aeruginosa as a causative agent of dermatitis in fleecerot, it is likely that the repertoire of extracellular products, such as exotoxin A, haemolysin and proteases, known to be produced by $P$. aeruginosa in other disease syndromes may be involved in the initiation of skin lesions. Another extracellular enzyme, phospholipase C (PLC), may function as a virulence factor since it causes skin lesions in rabbits (Liu, 1976), while a similar enzyme isolated from Clostridium species and known as alpha-toxin has been reported to be a major dermonecrotic toxin (Macfarlane \& Knight, 1941). However, to establish a possible

† Present address: Animal Science Research, Merck, Sharp and Dohme, PO Box 135, Ingleburn, Sydney, NSW 2565, Australia.

Abbreviations: AP, alkaline phosphatase; PLC, phospholipase C; PNPP, p-nitrophenyl phosphate; NPPC, $p$-nitrophenylphosphorylcholine; CTMAB, cetyltrimethylammonium bromide; TDTAB, tetradecyltrimethylammonium bromide; TMM, tryptose minimal medium; Tw, Tween 80. 
role for PLC as a dermonecrotizing agent in fleecerot, it was necessary to derive growth conditions favourable for the increased production of PLC in primary cultures of $P$. aeruginosa isolated from fleecerot lesions. Enhanced production of PLC from wild-type cultures would facilitate purification of the enzyme, in contrast to the generation, isolation and use of special PLC-producing mutants (Berka \& Vasil, 1982) whose biological properties may have been adversely affected by chemical or ultraviolet mutagenesis. This paper describes the use of Tween for enhanced production of PLC in a field strain of $P$. aeruginosa. The enzyme has been partially purified and some of its biological and immunological effects on sheep skin examined.

\section{METHODS}

Source and growth of P. aeruginosa. P. aeruginosa strain PL42 (identified with a Pseudomonas aeruginosa Antisera Set, Serotype 1; Difco) was isolated originally from a sheep with fleecerot. A lyophilized culture was revived and expanded on sheep blood agar. After incubation for $16 \mathrm{~h}$ at $30^{\circ} \mathrm{C}$, the bacterium was washed off the plate with sterile saline $(0.15 \mathrm{M}-\mathrm{NaCl})$ and adjusted spectrophotometrically to an $\mathrm{OD}_{650}$ of 0.4 . Portions $(2.5 \mathrm{ml})$ of this suspension were then inoculated into $250 \mathrm{ml}$ tryptose minimal medium (TMM; Stinson \& Hayden, 1979) with or without $0.5 \%(\mathrm{w} / \mathrm{v})$ polyoxyethylene sorbitan monolaurate (Tween 80 , or Tw). TMM contained $120 \mathrm{mM}-\mathrm{Tris} / \mathrm{HCl}$ (pH 7.2), $0.1 \%$ (v/v) tryptose (Difco), $20 \mathrm{~mm}-\left(\mathrm{NH}_{4}\right)_{2} \mathrm{SO}_{4}, 1.6 \mathrm{mM}-\mathrm{CaCl}_{2}, 10 \mathrm{mM}-\mathrm{KCl}$ and $50 \mathrm{~mm}$-glucose.

Cultures were maintained at $30^{\circ} \mathrm{C}$ for $30 \mathrm{~h}$ and aerated by stirring with a magnetic flea driven by a stirrer (Wheaton Biostir C) operating at 350 r.p.m. Samples $(5 \mathrm{ml})$ were removed aseptically at specified times for $\mathrm{OD}_{650}$ estimations. A portion was plated by limiting dilution on sheep blood agar to assess the number of colony-forming units (c.f.u.) while the remainder was passed through a $0.22 \mu \mathrm{m}$ Millipore filter and the ultrafiltrate assayed for enzyme activity.

Purification of PLC. PLC was purified by ion-exchange chromatography on DEAE-Sephacel (Pharmacia). An $18 \mathrm{~h}$ TMM + Tw broth culture was clarified by centrifugation $\left(2500 \mathrm{~g}_{\mathrm{av}}, 20 \mathrm{~min}\right)$. The PLC-enriched supernatant ( $250 \mathrm{ml})$ was concentrated 10- to 20-fold in an Amicon stirred cell equipped with a PM10 (10 kDa cut-off) membrane. The ultraconcentrate $(10 \mathrm{ml})$ was then dialysed against $25 \mathrm{mM}-\mathrm{Tris} / \mathrm{HCl}(\mathrm{pH} 7.9)$ and the volume adjusted to $15 \mathrm{ml}$ prior to loading onto a DEAE-Sephacel column $(10 \times 2.6 \mathrm{~cm})$ equilibrated in the same buffer. Unbound protein was washed of the column with equilibrating buffer before the application of a salt gradient ( 0 to $1 \mathrm{M}-\mathrm{NaCl}$ ) in $25 \mathrm{~mm}-\mathrm{Tris} / \mathrm{HCl}(\mathrm{pH} 7.9)$. Finally, a detergent wash $[1 \%$, w/v, cetyltrimethylammonium bromide (CTMAB) in $25 \mathrm{mM}-\mathrm{Tris} / \mathrm{HCl}, \mathrm{pH} 7.9$ ] was applied to the column immediately after the salt gradient to elute any tenaciously-bound protein. Fractions of $5 \mathrm{ml}$ were collected and protein was monitored by absorbance at $280 \mathrm{~nm}$. Samples from each eluted fraction were assayed for alkaline phosphatase (AP), PLC and haemolytic activity. Fractions with demonstrable PLC and haemolytic activity were pooled and further concentrated by dialysis against Aquacide (BDH). Usually, about $500-1000 \mu \mathrm{g}$ protein (obtained by scaled-up ion-exchange

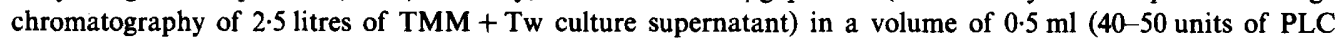
activity per $\mu \mathrm{g}$ protein) was loaded and chromatographed on a Sephacryl $S 200(37 \times 1.6 \mathrm{~cm})$ column equilibrated in $25 \mathrm{~mm}-\mathrm{Tris} / \mathrm{HCl}(\mathrm{pH} 7.9)$ containing $0.4 \mathrm{M}-\mathrm{NaCl}$. A single peak which retained both PLC and haemolytic activity was eluted at a flow rate of $0.4 \mathrm{ml} \mathrm{min}^{-1}$. This fraction was used in all subsequent ELISA assays for antiPLC activity and also for intradermal injections in sheep.

Experimental challenge inoculation of wet fleece with PL42. To simulate natural rain conditions, four sheep were maintained in a closed environment under an artificial sprinkler system. Wetting occurred twice a day for 1 week. These sheep were not challenge-inoculated. A second group of four sheep was challenged by seeding $10 \mathrm{ml}$ volumes of a suspension of $P$. aeruginosa PL42 in saline $\left(2 \times 10^{9}\right.$ c.f.u. $\left.\mathrm{ml}^{-1}\right)$. Post-inoculation humidity was maintained for 1 week by daily wetting with sterile water from a wash bottle along the sheep's back. A control group of another four sheep was kept dry throughout the experiment. Blood was collected from all 12 sheep just before the start of the experiment, and again 2 weeks later. All sera were analysed in an ELISA test for anti-PLC activity.

Skin washings. These were done on the four dry, the four wetted and non-challenged, and the four wetted and challenged sheep, 1 week after the start of the experiment. Wool overlying the skin surface was removed with curved scissors and an open-ended glass cylinder $(6 \mathrm{~cm}$ diameter by $8 \mathrm{~cm}$ long) was affixed end-on by firm pressure onto the skin surface. Then $20 \mathrm{ml}$ saline containing $0.1 \%(\mathrm{w} / \mathrm{v})$ Triton X-100 was introduced into the glass cylinder and the skin surface was washed rigorously by repeated jetting of the detergent solution with a sterile $10 \mathrm{ml}$ pipette. This process was repeated with fresh detergent solution and pooled washings were passed through a coarse filter (Whatman no. 41), and then successively through a $0.45 \mu \mathrm{m}$ and a $0.22 \mu \mathrm{m}$ filter (Millipore). Samples of skin washings were assayed for AP and PLC activity.

Intradermal injections of PLC. Two sheep were shorn of their fleece cover using electric shears. Care was taken not to nick the skin. Intradermal injections were given using a 28 gauge needle and a $1 \mathrm{ml}$ syringe. PLC at $0 \cdot 1,0.01$ and $0.001 \mathrm{mg}$ in a final volume of $0.1 \mathrm{ml}$ was administered randomly at five separate sites for each dose per sheep. 
ELISA detection of antibodies against AP or PLC. Assays for antibody against AP or PLC were done by ELISA as described by Chin et al. (1986). AP or PLC was coupled to microtitre plates at a concentration of $10 \mu \mathrm{g} \mathrm{ml}^{-1}$ in $0.035 \mathrm{M}$-sodium bicarbonate buffer ( $\mathrm{pH} 9 \cdot 5$ ). Binding of sheep antibodies to the assay antigen was detected with a monoclonal second antibody (ARIMab) which possesses broad-spectrum reactivity against all ruminant immunoglobulins (unpublished results).

Enzyme assays. PLC was assayed in a microtitre plate with p-nitrophenylphosphorylcholine (NPPC) as the substrate according to Kurioka \& Matsuda (1976). AP activity was determined by hydrolysis of $p$-nitrophenyl phosphate (PNPP) essentially as described by Chin (1983). Enzymic activity is expressed in units where a unit(U) is defined as the amount of enzyme required to release $1 \mathrm{nmol} p$-nitrophenol per min at $21^{\circ} \mathrm{C}$.

Haemolytic assays. Fractions eluted from the DEAE-Sephacel column were diluted $(0.1 \mathrm{ml}+0.9 \mathrm{ml})$ with $0.15 \mathrm{M}-\mathrm{NaCl}$ containing $10 \mathrm{mM}-\mathrm{CaCl}_{2}$. Sheep erythrocytes $(1.0 \mathrm{ml}$ of $0.5 \%, \mathrm{v} / \mathrm{v}$, suspension) in saline were added to each assay and incubated at $37^{\circ} \mathrm{C}$ for $1 \mathrm{~h}$. The unlysed erythrocytes were then sedimented by centrifugation $\left(2500 \mathrm{~g}_{\mathrm{av}}, 15 \mathrm{~min}\right)$. The supernatant was removed and the $A_{545}$ determined. Results were expressed as a percentage of the complete lysis of an equivalent amount of sheep erythrocytes (lysed in distilled water).

$S D S-P A G E$. This was done as described by Laemmli (1970) in a Hoefer SE200 mini-gel electrophoresis system, using $10 \%(\mathrm{w} / \mathrm{v})$ polyacrylamide. Each track was loaded with $10-50 \mu \mathrm{g}$ protein. Gels were stained with Coomassie Brilliant Blue 250. The molecular mass of subunit protein was determined under reducing conditions with reference to a set of low molecular mass standards (Bio-Rad).

\section{RESULTS}

\section{Growth of $P$. aeruginosa in TMM with and without $T w$}

The field isolate of $P$. aeruginosa, strain PL42, was inoculated in TMM with or without Tw at an initial inoculum density of $5 \times 10^{5}$ c.f.u. $\mathrm{ml}^{-1}$. Growth, as determined by an increase in $\mathrm{OD}_{650}$ (Fig. 1), in either medium was characterized by a $2-6 \mathrm{~h}$ lag phase. In the presence of $\mathrm{Tw}$, the exponential growth phase was restricted to $5-8 \mathrm{~h}$, with growth curves reaching a plateau after $20 \mathrm{~h}$. In contrast, cultures grown in the absence of Tw maintained a 15-20 h exponential growth phase which levelled off after $30 \mathrm{~h}$. Limiting dilution plating was done on culture samples at $25 \mathrm{~h}$ to ensure that increases in $\mathrm{OD}_{650}$ were not caused by cell lysis. At this time, a cell density of $3.38 \times 10^{7}$ c.f.u. $\mathrm{ml}^{-1}$ and $5.2 \times 10^{7}$ c.f.u. $\mathrm{ml}^{-1}$ was reached in the presence and absence of $T w$ respectively. The concentration of $T w$ used in these experiments was $0.5 \%(v / v)$. Increasing $T w$ to $1 \%(\mathrm{v} / \mathrm{v})$ further suppressed growth while $2 \%(\mathrm{v} / \mathrm{v})$ completely inhibited cell proliferation.

\section{Exocellular PLC and AP activities in TMM $+T w$}

Triplicate $50 \mu \mathrm{l}$ samples of the clarified culture supernatant were assayed at different times during the culture period for PLC and AP activity. In the presence of Tw, the highest level of PLC detected was at $18 \mathrm{~h}$ and this level of enzyme activity was 12 times that in the absence of Tw (Fig. 2). The level of AP activity at $18 \mathrm{~h}$ was also higher in the presence of Tw. The production of AP in Tw-free TMM did not appear to parallel the growth characteristics of PL42 (Fig. 2) and decreased while growth was still exponential. In contrast, PLC production in TMM + Tw reached a maximum at the end of exponential growth.

In the absence of $\mathrm{Tw}$, the $\mathrm{pH}$ of the culture medium remained relatively stable over $25 \mathrm{~h}$, decreasing from 7.2 to 6.4 . In contrast, cultures grown in the presence of Tw showed a rapid decrease in $\mathrm{pH}$ from 7.2 to 4.7 over the same time period. This probably accounted for the earlier arrested growth rate observed in cultures containing $\mathrm{Tw}$.

\section{Purification of PLC}

Clarified supernatants from cultures grown for $18 \mathrm{~h}$ in TMM + Tw (containing maximum detectable levels of PLC) were used for enzyme purification. Each ion-exchange column was usually loaded with $15 \mathrm{ml}$ of culture supernatant concentrated from $250 \mathrm{ml}$ of original culture medium. A typical elution profile is shown in Fig. 3. An unbound peak (A) enriched in AP was eluted with $25 \mathrm{~mm}$-Tris/HCl, $\mathrm{pH} 7 \cdot 9$. Application of a 0 to $1 \mathrm{M}-\mathrm{NaCl}$ gradient eluted two additional peaks ( $B$ and $C$ ) which contained only PLC activity. At the end of the salt gradient, a detergent elution was done with CTMAB, since Berka \& Vasil (1982) reported that PLC bound 


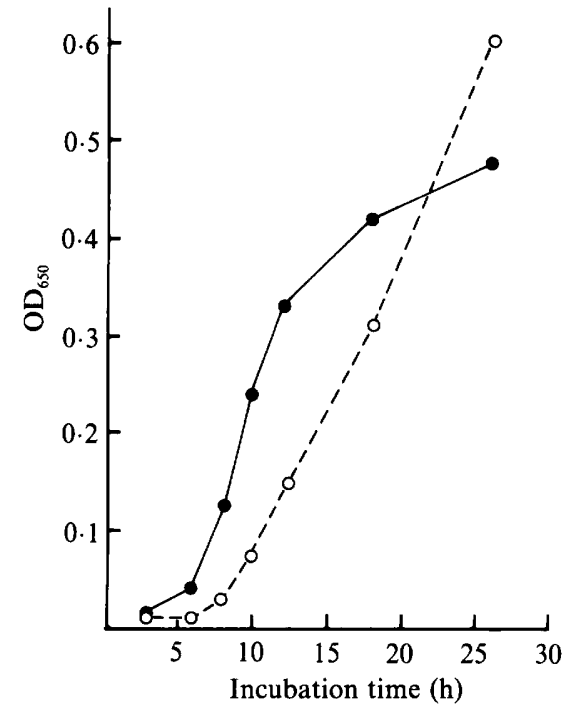

Fig. 1

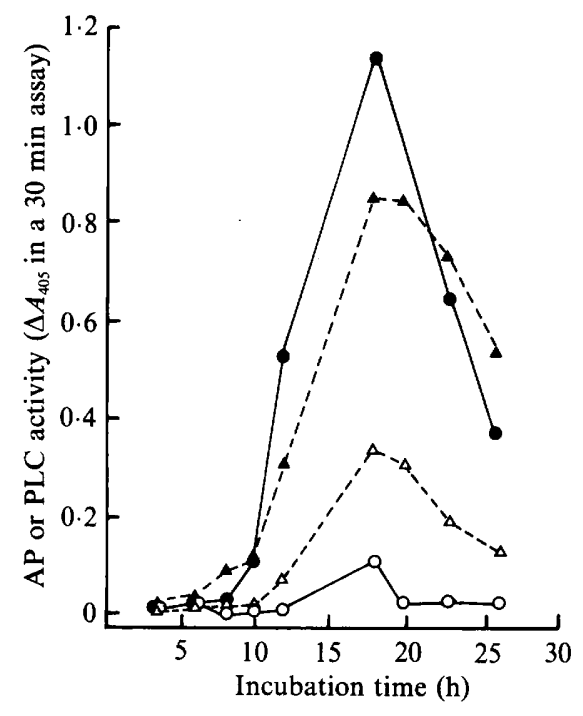

Fig. 2

Fig. 1. Growth of $P$. aeruginosa PL42 in the presence $(\bullet)$ or absence $(0)$ of Tw $(0.5 \%, w / v)$ in TMM. Samples were removed at specific times from a $250 \mathrm{ml}$ culture and their $\mathrm{OD}_{650}$ determined. The experiment was repeated twice with essentially similar results.

Fig. 2. Effect of Tw on the production of PLC and AP in the culture supernatant. AP (---) and PLC $(\longrightarrow)$ assays were done on the supernatants of cultures with $(\bullet, \Delta)$ and without $(O, \triangle)$ Tw, activity being measured as the release of $p$-nitrophenol in a $30 \mathrm{~min}$ assay. Essentially similar results were obtained in a repeat experiment.

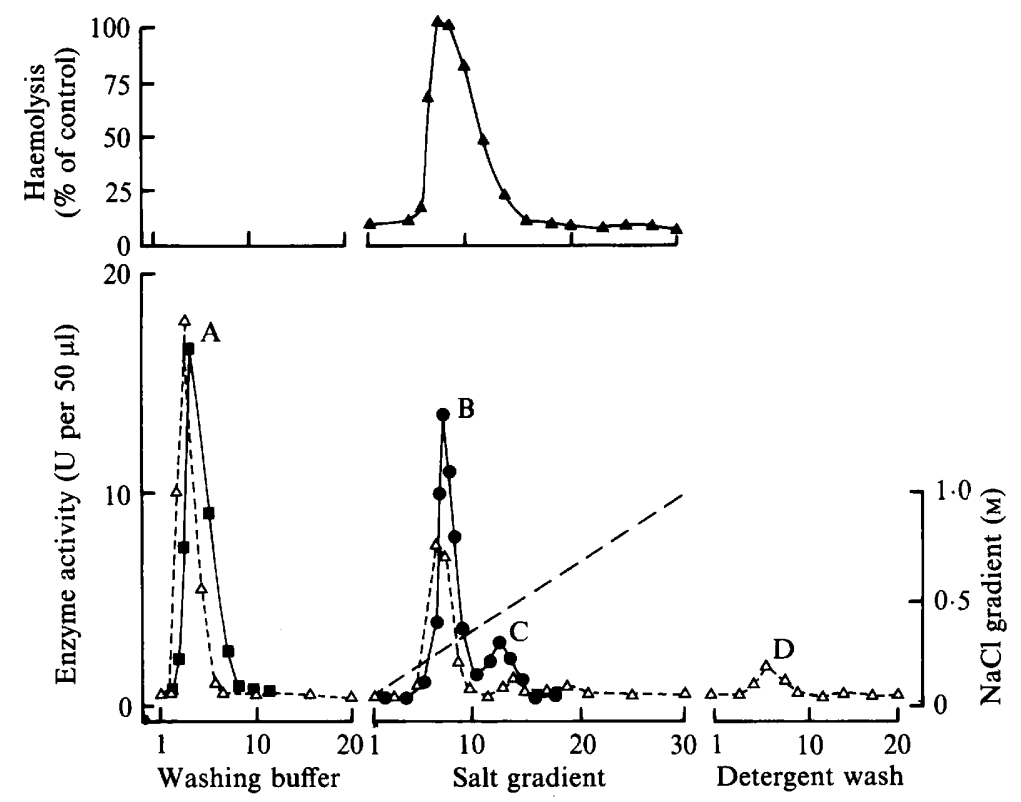

Fraction number

Fig. 3. Enzymic and haemolytic activities of PLC and AP present in the fractions collected during ionexchange chromatography, on a DEAE-Sephacel column, of concentrated Tw-containing supernatants. Upper panel: $\boldsymbol{\Lambda}$, haemolytic activity expressed as a percentage of complete haemolysis of sheep erythrocytes by water. Lower panel: $\triangle, A_{280}$; $\boldsymbol{\square}$, AP activity; $\bullet$, PLC activity. Essentially similar results were obtained in at least four other separate experiments. 


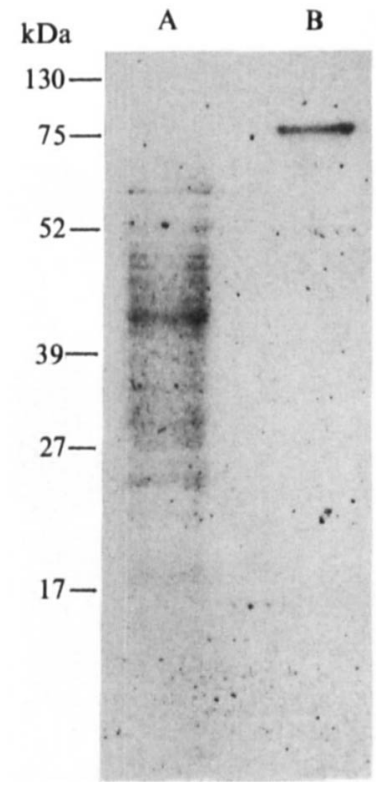

Fig. 4. SDS-PAGE of PM10-concentrated broth culture (lane A) and PLC after Sephacryl S-200 chromatography (lane B) run under reducing conditions in a $10 \%$ polyacrylamide gel.

Table 1. Purification of PLC from TMM + Tw broth

$\begin{array}{lrrcccc}\text { Purification step } & \begin{array}{c}\text { Volume } \\ (\mathrm{ml})\end{array} & \begin{array}{c}\text { Protein } \\ (\mu \mathrm{g})\end{array} & \begin{array}{c}\text { Specific activity } \\ {\left[\mathrm{U}(\mu \mathrm{g} \text { protein })^{-1}\right]}\end{array} & \begin{array}{c}\text { Recovery of } \\ \text { activity (\%) }\end{array} & \begin{array}{c}\text { Purification } \\ (-\mathrm{fold})\end{array} \\ \text { atant } & 250 & 21250 & 0 \cdot 5 & 100 & 1 \\ \text { rated supernatant } & 15 & 8600 & 0 \cdot 78 & 62 & 1 \cdot 5 \\ \text { rer ion-exchange chromatography } & 5 & 44 & 48 \cdot 7 & 48 & 97\end{array}$

tenaciously to ion-exchange resins so that desorption could be achieved only with tetradecyltrimethylammonium bromide (TDTAB). A small protein peak (D) was obtained which contained neither AP nor PLC activity.

The ability of individual fractions separated by ion-exchange chromatography to lyse sheep erythrocytes was examined semi-quantitively (Fig. 3, upper panel). The AP-containing peak A possessed no haemolytic activity; haemolysis was confined essentially to peak B (PLC). Fractions constituting this PLC peak were pooled, concentrated by dialysis against Aquacide and applied to a Sephacryl S-200 column. A single major peak with an estimated molecular mass of $80 \mathrm{kDa}$ was eluted and this contained all the PLC activity (data not shown). SDS-PAGE analysis of the Sephacryl S-200 peak under reducing conditions (Laemmli, 1970) revealed a major band with an apparent molecular mass of $80 \mathrm{kDa}$ (Fig. 4). Peak $\mathrm{C}$ fractions contained detectable but low levels of PLC activity. None of these fractions lysed sheep erythrocytes.

The purification and percentage recovery of PLC which retained both enzymic and haemolytic activity are summarized in Table 1 . Pooled peak B fractions contained $48 \%$ of the total PLC activity detected in TMM + Tw, and the enzyme had been purified 97 -fold. This enzyme was relatively unstable; it could be stabilized by the addition of sorbitol to $60 \%(\mathrm{w} / \mathrm{w})$ in $25 \mathrm{mM}$-Tris/ $\mathrm{HCl}, \mathrm{pH} 7.2$ (unpublished). Further chromatography on a molecular sieve column failed to increase purification and was associated with a further loss in activity (20-30\% recovery).

\section{Effect of PLC on sheep skin}

In the natural environment of wet fleece, $P$. aeruginosa colonizes the skin surface and is noninvasive during fleecerot formation. As shown in Fig. 5(a), skin sections from natural fleecerot 

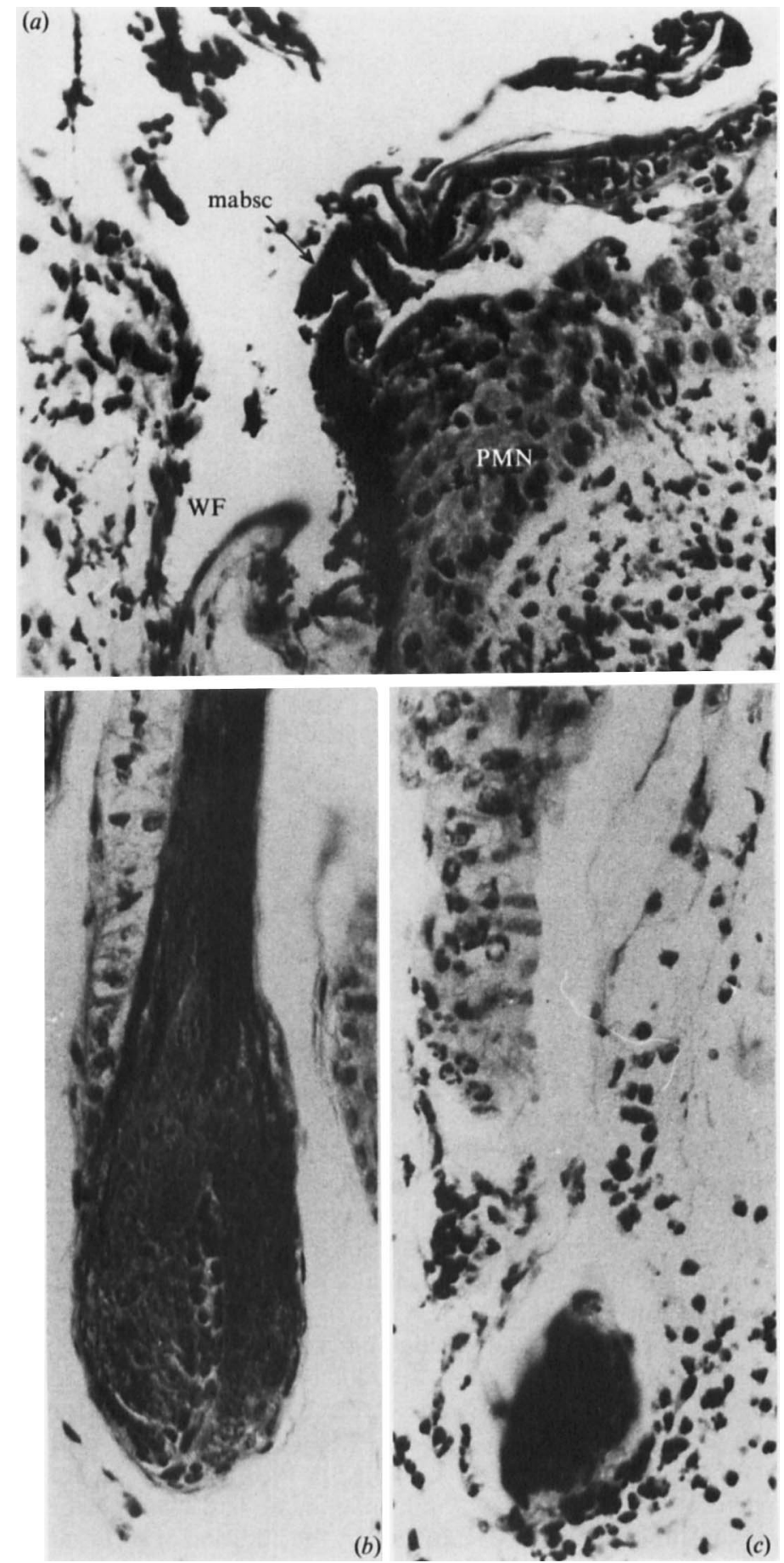

Fig. 5. Vertical skin sections from sheep (magnification $\times 312)$. $(a)$ Lower half of wool follicle and dermal tissue from a natural fleecerot lesion. A microabscess (mabsc) at the outer margin of a wool follicle has formed by infiltration of polymorphonucleocytes (PMN). Note that the margins of the wool follicle (WF) are completely lysed. (b) An intact wool follicle from normal sheep skin. (c) Extensive necrosis of the follicular and epidermal margins of a wool follicle following intradermal injection with PLC. As in (a), inflammatory cells comprising predominantly polymorphonuclear leucocytes have infiltrated the necrotic cell zones. 
Table 2. AP and PLC activity from skin washings of fleecerot-affected sheep and their anti-PLC antibody levels compared to animals that had been injected intradermally with PLC

\begin{tabular}{|c|c|c|c|c|c|}
\hline \multirow[b]{2}{*}{ Treatment } & \multirow{2}{*}{$\begin{array}{l}\text { Number } \\
\text { of sheep }\end{array}$} & \multicolumn{2}{|c|}{$\begin{array}{c}\text { Activity in } \\
\text { skin washings* }\end{array}$} & \multicolumn{2}{|c|}{$\begin{array}{l}\text { Anti-PLC antibody } \\
\left.\text { (ELISA } A_{492}\right) \dagger\end{array}$} \\
\hline & & AP & PLC & Before wetting & After wetting \\
\hline $\begin{array}{l}\text { Dry/not challenged } \\
\text { Wetted/not challenged } \\
\text { Wetted/challenged }\end{array}$ & $\begin{array}{l}4 \\
4 \\
4\end{array}$ & $\begin{array}{c}<1 \\
137 \pm 15 \\
248 \pm 11\end{array}$ & $\begin{array}{c}<1 \\
26 \pm 8 \\
87 \pm 9\end{array}$ & $\begin{array}{l}0 \cdot 18 \pm 0.08 \\
0 \cdot 16 \pm 0.09 \\
0.20 \pm 0.1\end{array}$ & $\begin{array}{c}\text { NA } \\
0.95 \pm 0.18 \\
1.43 \pm 0.25\end{array}$ \\
\hline $\begin{array}{l}\text { Intradermal injection of PLC } \\
\text { NA, Not applicable. } \\
\text { * Results represent the mean } \\
\text { expressed as U (mg protein) } \\
\text { † Blood was collected prior to } \\
\text { animals were bled again } 2 \text { week } \\
\text { activity by ELISA. The result }\end{array}$ & $\begin{array}{l}\text { EM of six } \\
\text { ting (wit } \\
\text { er. Serun } \\
\text { means }\end{array}$ & $\begin{array}{l}\text { ings from } \\
\text { ithout ch } \\
\text { diluted } 1\end{array}$ & NA & $0 \cdot 17 \pm 0 \cdot 05$ & $0.64 \pm 0.13$ \\
\hline
\end{tabular}

dermatitic lesions are characterized by dense infiltration of leucocytes with ensuing exocytosis of predominantly polymorphonucleocytes as a microabscess (arrowed) in the epidermis. Commonly, these microabscesses develop at the outer margins of wool follicles and eventually discharge their seropurulent contents onto the skin surface. Follicle bulb cells are characteristically lysed in situ (Fig. 5a) by presumptive PLC activity; this contrasts sharply with the morphology of a normal wool follicle (Fig. $5 b$ ).

A role for PLC of $P$. aeruginosa strain PL42 as a dermonecrotizing agent was investigated by intradermal injection of the enzyme followed by histological analysis. Sections of skin biopsied $24 \mathrm{~h}$ after exposure to PLC at a dose of $0.1 \mathrm{mg}$ per injection site revealed the presence of a central abscess with extensive liquefactive necrosis of the wool follicles (Fig. $5 c$ ). With $0.01 \mathrm{mg} \mathrm{PLC,} \mathrm{a}$ less severe dermatitic response was noted (similar to Fig. $5 a$ ) and this was characterized by dense infiltration of predominantly polymorphonuclear leucocytes into the dermis. Intradermal injections with varying doses $(0 \cdot 1-0.001 \mathrm{mg}$ ) of partially purified AP (peak A), failed to elicit the inflammatory responses observed with PLC.

\section{Immunological response to PLC in sheep affected with fleecerot}

In a limited study, fleecerot dermatitis was initiated in sheep under different conditions. In the first case, four sheep were wetted in an artificial water sprinkler system (as described in Methods) to simulate natural rainfall, but were not challenged with $P$. aeruginosa. They developed characteristic greening lesions after about 3-4 d. A second group of four animals was similarly wetted except that the sheep were also challenged with $P$. aeruginos $a$. These challenged animals developed greening lesions $12-14 \mathrm{~h}$ later.

As shown in Table 2, proliferating fleece bacteria identified microbiologically as $P$. aeruginosa and also by virtue of the characteristic greening lesions of the fleece (unpublished observations), produced assayable quantities of AP and PLC in skin washings. Similar washings from unwetted, unchallenged sheep showed no detectable enzyme activity. The activities of AP and PLC in skin washings from wetted and challenged sheep 1 week after treatment were much higher than those in wetted and unchallenged animals. Accordingly, higher levels of anti-PLC activity were detected in the sera of wetted and challenged sheep compared to their unchallenged counterparts. Intradermal injections of PLC did not elicit as high a level of antiPLC activity as found in the sera of sheep experiencing fleecerot (either wetted, or wetted and challenged). Pre-incubation of anti-PLC serum (from sheep that had been wetted, wetted and challenged, or injected intradermally) with PLC for $1 \mathrm{~h}$ at $37^{\circ} \mathrm{C}$ did not inhibit the enzymic activity of PLC when compared to similar incubations using control sera collected from the same sheep before the experiment. All control sera possessed only background levels of antiPLC activity ( $<0.2$ ELISA $A_{492}$ units). 


\section{DISCUSSION}

Of several exocellular products excreted by $P$. aeruginosa, PLC and an associated haemolysin have been described as dermonecrotizing agents (Kurioka \& Liu, 1967). P. aeruginosa, under conditions of phosphate limitation, synthesizes and releases into the culture medium an inducible AP and PLC (Poole \& Hancock, 1983). Although the mechanism for AP and PLC release has not been clearly defined, it may occur after membrane perturbation or destabilization with Tris-based medium (Bhatti \& Ingram, 1982; Irvine et al., 1981) or by cold shock treatment (Hoshino \& Kageyama, 1980). In preliminary experiments, we attempted to elicit PLC production by membrane perturbation using detergents such as Triton X-100, Nonidet P40 and Tween 80 in cultures grown under phosphate-limited conditions. Growth of PL42 was inhibited to varying degrees by all three detergents, depending upon the concentration. Only with Tween 80 was growth considered to be satisfactory $(60-80 \%$ of that in the absence of detergent) and this was accompanied by a 12-fold increase in PLC production. Under similar conditions, the level of detectable AP in TMM + Tw was only 2 to 2.5 times that in the absence of $\mathrm{Tw}$.

To investigate the role of PLC as a virulence component in fleecerot, it was necessary to purify the enzyme from its major contaminant - AP. This was accomplished by ion-exchange chromatography, where $A P$ was not retained on a range of anion resins tested including DEAEAffi-gel Blue (Bio-Rad), DEAE-Sephacel (Pharmacia) and Trisacryl DEAE (Linbrook, LKB). PLC bound to and could be eluted under low salt conditions from all three anion-exchange resins. This property differs significantly from that described by Berka \& Vasil (1982), who found that under their conditions PLC bound tenaciously to anion resins and could be eluted only with a quaternary ammonium detergent (TDTAB). It is likely that the PLC produced by the PLC-hyperproducing strain of the latter authors, which was isolated after chemical mutagenesis of $P$. aeruginosa PAO1, may differ in charge from the PLC produced by the natural fleecerot isolate.

The ion-exchange conditions used for the purification of PLC from supernatants of cultures grown in TMM + Tw permitted the identification of two peaks (B and C) with PLC activity. Only peak B possessed haemolytic activity in addition to enzymic activity against NPPC. It is conceivable that peak C is either one of two different isoenzymic forms of PLC (Berk et al., 1987) or it is a denatured form of PLC which has lost its haemolytic activity.

Although the biological activity of peak B PLC from strain PL42 was confirmed by haemolysis of sheep erythrocytes, its role in eliciting dermatitis was further tested by intradermal injection of varying doses of the enzyme into the skin on the back of shorn sheep. The ensuing dermatitis and folliculitis associated with such treatment, although deep-seated, was nevertheless remarkably similar to that seen in skin sections from natural fleecerot lesions. Unpublished results using intradermal injections of crude culture supernatants devoid of PLC but containing high levels of proteolytic elastase and collagenase activity failed to elicit equivalent pathology. AP was neither haemolytic nor dermatitic.

Sheep after experiencing several fleecerot episodes should become sensitized to one or several exoenzymes produced by $P$. aeruginosa. When analysed by ELISA, serum from sheep with fleecerot contained high levels of circulating antibody against PLC. However, these antibodies were incapable of neutralizing PLC activity in situ, and it is likely that the enzyme molecule may contain immunodominant epitopes at non-catalytic site(s). It is interesting that although proliferating $P$. aeruginosa produces AP as well as proteolytic enzymes on the wet sheep skin, the humoral immune system of the sheep recognizes PLC as the dominant immunogen. It therefore appears unlikely that protection against fleecerot by immunization with crude bacterins or concentrated culture supernatants enriched in exoenzymes (Burrell et al., 1982a; Burrell, 1985) may be effective as a result of antibody neutralization of dermatitic enzymes of $P$. aeruginosa, unless such antibodies can be targeted to the active site and shown to inactivate enzyme function.

This project was supported by a grant (DAN 19S) from the Wool Research and Development Fund on the recommendation of the Australian Wool Corporation. The authors would also like to thank J. Dennis and N. Kandarajah for technical assistance. 


\section{REFERENCES}

Berk, R. S., Brown, D., Coutinho, I. \& Meyers, D. (1987). In vivo studies with two phospholipase C fractions from Pseudomonas aeruginosa. Infection and Immunity 55, 1728-1730.

Berka, R. M. \& VAsil, M. L. (1982). Phospholipase C (heat-labile haemolysin) of Pseudomonas aeruginosa. Purification and preliminary characterization. Journal of Bacteriology 152, 239-245.

Bhatti, A. R. \& INGRam, J. M. (1982). The binding and secretion of alkaline phosphatase by Pseudomonas aeruginosa. FEMS Microbiology Letters 13, 353-356.

BURRELL, D. H. (1985). Immunisation of sheep against experimental Pseudomonas aeruginosa dermatitis and fleece-rot associated body strike. Australian Veterinary Journal 62, 55-57.

Burrell, D. H., Merritt, J. C., Watts, J. E. \& WALKER, K. H. (1982a). The role of Pseudomonas aeruginosa in pathogenesis of fleece rot and the effect of immunization. Australian Veterinary Journal 58, 34-35.

Burrell, D. H., Merritt, J. C., Watts, J. E. \& WALKER, K. H. $(1982 b)$. Experimental production of dermatitis in sheep with Pseudomonas aeruginosa. Australian Veterinary Journal 59, 140-144.

CHIN, J. (1983). Comparison of different antigenic preparations for the detection of ovine serum antibodies against Brucella ovis by ELISA. Australian Veterinary Journal 60, 261-263.

Chin, J. C., Scully, C. \& PANG, B. (1986). Monoclonal antibodies against ovine IgA purified from lung lavage fluid. Research in Veterinary Science 41, 102107.

Hollis, D. E., Chapman, R. E. \& Hemsley, J. A. (1982). Effects of experimentally induced fleecerot on the structure of the skin of Merino sheep. Australian Journal of Agricultural Research 35, 545556.
Hoshino, T. \& Kageyama, M. (1980). Purification and properties of a binding protein for branched-chain amino acids in Pseudomonas aeruginosa. Journal of Bacteriology 141, 1055-1056.

Irvine, R. J., MACAlister, T. J. \& Costerton, J. W. (1981). Tris(hydroxymethyl)methane buffer modifcation of Escherichia coli outer membrane permeability. Journal of Bacteriology 145, 1397-1403.

Kurioka, S. \& LiU, P. V. (1967). Effect of the hemolysin of Pseudomonas aeruginosa on phosphatides and on phospholipase $C$ activity. Journal of Bacteriology 93, 670-674.

Kurioka, S. \& Matsuda, M. (1976). Phospholipase C assay using $p$-nitrophenylphosphorylcholine together with sorbitol and its application to studying the metal and detergent requirement of the enzyme. Analytical Biochemistry 75, 281-289.

LAEMMLI, U. K. (1970). Cleavage of structural proteins during the assembly of the head of bacteriophage T4. Nature, London 227, 680-685.

LIU, P. V. (1976). Biology of Pseudomonas aeruginosa. Hospital Practice 11, 138-147.

Macrarlane, M. G. \& KNight, B. C. J. G. (1941). The biochemistry of bacterial toxins. I. The lecithinase activity of Clostridium welchii toxins. Biochemical Journal 35, 884-902.

MERRITT, G. C. \& WATTS, J. E. (1978). The changes in protein concentration and bacteria of fleece and skin during the development of fleece rot and bodystrike in sheep. Australian Veterinary Journal 54, 513.

PoOLe, K. \& Hancock, R. E. W. (1983). Secretion of alkaline phosphatase and phospholipase $\mathrm{C}$ in Pseudomonas aeruginosa is specific and does not involve an increase in outer membrane permeability. FEMS Microbiology Letters 16, 25-29.

StInSON, M. W. \& HAYDEN, C. (1979). Secretion of phospholipase $\mathrm{C}$ by Pseudomonas aeruginosa. Infection and Immunity 25, 558-564. 